\title{
Mindfulness-Based Stress Reduction for Integrative Cancer Care - a Summary of Evidence
}

\author{
Frauke Musial $^{\mathrm{a}} \quad$ Arndt Büssing $^{\mathrm{b}} \quad$ Peter Heusser $^{\mathrm{b}} \quad$ Kyung-Eun Choi $^{\mathrm{c}} \quad$ Thomas Ostermann $^{\mathrm{b}}$ \\ ${ }^{a}$ The National Research Center in Complementary and Alternative Medicine (NAFKAM), Department of Community Medicine, \\ Faculty of Health Science, University of Troms $\varnothing$, Norway \\ ${ }^{\mathrm{b}}$ Center for Integrative Medicine, Faculty of Health, University of Witten/Herdecke, \\ ${ }^{\mathrm{C}}$ Chair of Complementary and Integrative Medicine, University of Duisburg-Essen, Essen, Germany
}

\section{Keywords}

Meta-analysis · Mindfulness · MBSR · Integrative oncology · Cancer patients - Systematic review · Mind-body relation

\section{Summary}

This paper provides a comprehensive overview of the relevant existing evidence, and critically appraises the use of mindfulness-based stress reduction (MBSR) in cancer care. Furthermore, a meta-analysis was conducted in order to investigate the effect of MBSR on quality of life ( $\mathrm{OoL})$, mood, and distress. Besides 6 reviews (5 systematic, 1 meta-analytic) which are reported separately, a total of 19 original research papers fully met the inclusion criteria for the systematic review. The 19 original papers consisted of 5 randomised controlled trials (RCTs), 4 non-randomised controlled trials (NRCTs), 9 observational studies (OS) and 1 two-arm observational study. The included outcome measures were QoL, mood, and distress. Cohen's effect size d was computed for each category. Estimating the effect on QoL, a total of $n=248$ patients out of 6 studies was included and the overall effect size was 0.29 (95\% confidence interval (CI) $0.17-0.40 ; p \leq 0.00005)$. Calculating the effect on mood, a total of $n=411$ patients out of ten studies were included, and the overall effect size was 0.42 (95\% $\mathrm{Cl} 0.26-0.58 ; \mathrm{p}<0.0001)$. Reduction in distress revealed an overall effect size of 0.58 (95\% Cl $0.45-0.72 ; \mathrm{p}<0.0001 ; \mathrm{n}=587$ patients out of 15 studies). MBSR programmes can improve QoL and mood, and reduce distress in cancer patients. However, there is an urgent need for more high quality RCTs implementing adequate controls, longer follow-up periods, sufficient samples sizes, clear descriptions of patients' psychological profiles, and the accompanying utilisation of qualitative measures.

\section{Schlüsselwörter}

Meta-Analyse - Achtsamkeit - MBSR - Integrative Onkologie · Krebspatienten · Systematischer Review · Mind-Body-Medizin

\section{Zusammenfassung}

Die vorliegende Arbeit versucht, einen umfassenden Überblick über die bestehende Evidenz zum Einsatz von MBSR(mindfulness-based stress reduction)-Programmen im Rahmen der onkologischen Therapie zu geben. Darüber hinaus wurde eine Meta-Analyse durchgeführt, um die Wirkung von MBSR auf die Lebensqualität (quality of life; $\mathrm{CoL}$ ), Stimmung und Stress eingehender zu untersuchen. Neben 6 Übersichtsarbeiten (5 systematische Reviews, 1 MetaAnalyse), die gesondert referiert werden, erfüllten insgesamt 19 Originalarbeiten die Einschlusskriterien. Von den 19 Originalarbeiten waren 5 Studien randomisiert und kontrolliert, 4 Studien waren nichtrandomisiert, aber kontrolliert, 9 waren Beobachtungsstudien, und eine Studie wurde als zweiarmige Beobachtungsstudie durchgeführt. Relevante Endpunkte waren QoL, Stimmung und Stress. Für jede Kategorie wurde Cohens d als Maß für die Effektstärke berechnet. Zur Abschätzung des Einflusses auf die QoL wurden insgesamt $\mathrm{n}=248$ Patienten aus 6 Studien in die Analyse eingeschlossen. Cohens d betrug 0,29 (95\%-Konfidenzinterval (95\%-KI) $0,17-0,40 ; p \leq 0,00005)$. Für die Variable Stimmung wurden insgesamt 411 Patienten aus zehn Studien einbezogen; der Gesamteffekt betrug 0,42 (95\%-KI 0,26-0,58; $p<0,0001)$. Für die Variable Stress ergab sich eine Effektstärke von 0,58 (95\%-KI 0,45-0,72; $\mathrm{p}<0,0001 ; \mathrm{n}=587$ Patienten aus 15 Studien). MBSR-Programme können die Lebensqualität und Stimmung von onkologischen Patienten verbessern und die subjektiv empfundene Belastung reduzieren. Nichtsdestotrotz besteht nach wie vor Bedarf an randomisierten-kontrollierten Studien hoher Qualität, mit angemessenen, aktiven Kontrollbedingungen, längerem Follow-up, ausreichender Stichprobengröße, klaren Beschreibungen der psychologischen Profile von Patienten sowie der vermehrten Integration qualitativer Forschungsmethoden.

\section{KARGER \\ Fax +497614520714 \\ Information@Karger.de}

www.karger.com (c) 2011 S. Karger GmbH, Freiburg

1661-4119/11/0184-0192\$38.00/0

Accessible online at:

www.karger.com/fok
Frauke Musial, $\mathrm{PhD}$

The National Research Center in Complementary and Alternative Medicine (NAFKAM)

Department of Community Medicine, Faculty of Health Sience, University of Troms $\varnothing$

9037 Troms $\varnothing$, Norway

Tel. +47 7764-9282, Fax -6647

frauke.musial@uit.no 


\section{Introduction}

Being diagnosed with cancer is generally experienced as a lifethreatening situation, resulting in a particularly high degree of emotional strain [1]. The fact, that a cancer diagnosis represents an 'existential plight' has long been recognised [2], and consequently, psychological and physical symptoms such as anxiety and depression, fatigue and sleep disturbance $[3,4]$ even to the degree of traumatisation [5] have been described. The 'existential plight' induced by a cancer diagnosis with all its consequences for the individual patient as a physical, mental and spiritual being thus should be recognised as a major source of suffering itself. Consequently, it is consensus that psychological interventions should be an integral part of cancer care (e.g. NICE http://guidance.nice.org.uk/Topic/Cancer). Complementary and alternative medicine involves a whole spectrum of therapeutic interventions including mind-body medicine (definition and overview: http://nccam.nih.gov/ health/whatiscam/). Therefore it is not surprising that the interest in integrative cancer care is steadily increasing among cancer patients and that a growing number of patients use mind-body interventions such as meditation as a self-help strategy to alleviate their suffering $[6,7]$. Nevertheless, utilisation of meditative approaches can also be the expression of a patient's reflection on what is essential in life (in terms of a reappraisal strategy) with subsequent changes of life concerns and behaviour. For several patients, these practises may reflect a vital search for meaning in life, or a search for an individual experience of the divine - which would transcendent the experience of suffering and illness [8]. A systematic survey revealed that an average of about $30 \%$ of cancer patients have tried complementary treatments [9], and consequently, many oncology centres provide some kind of complementary treatment [10].

\section{Mindfulness-Based Stress Reduction}

Mindfulness meditation is seen as a way to experience life in a 'non-judgemental' way, i.e., non-judgemental acceptance of the current situation (including symptoms of illness), and also mindful presence in the given situation (including negative emotions). The emphasis of mindfulness is placed on an observational orientation of what is happening, concerning thoughts and feelings in this very moment. Mindfulness exercises train to keep an observant, non-judgemental attitude to the present momentum without getting entangled in feelings of guilt or failure, desires, in memories of what was, or anticipations of what will be in the future. Full awareness of what happens in this very moment yet at the same time being able to release emotionally is incongruent with unpleasant memories or anticipated worries. Therefore, mindfulness is an attitude towards the presence rather than a technique to control unwanted feelings.
Mindfulness-based stress reduction (MBSR) is a structured, psychoeducational programme which combines yoga exercises, educational sequences on lifestyle, and a spectrum of mindfulness exercises with different mental foci such as a sitting exercise with a focus on breathing or the classical 'body scan'. It is a group-oriented programme, usually delivered in 8-12 sessions lasting $2.5 \mathrm{~h}$, and a retreat of a whole day. MBSR has often been successfully implemented in clinical settings [11-13] but is, however, not restricted to clinical populations. The basic idea of MSBR is the promotion of relaxation through the nonjudgmental, moment-to-moment awareness of internal and external sensations, experiences, and reactions concerning both body and mind. The MBSR programme delivers useful skills for coping with emotional distress and a variety of bodily symptoms and has been shown to be beneficial for a variety of diseases, especially pain and stress disorders [14-16], but also anxiety [17] and depression [18-20]. Stress, anxiety, depression, and often pain are among the core symptoms associated with cancer diagnosis and treatment. It is likely that MBSR provides a useful strategy for cancer patients to improve their psychosocial well-being under the circumstances of an often devastating diagnosis. Consequently, several studies investigating the effects of mindfulness meditation for oncology patients have been conducted.

\section{Reviews on Mindfulness-Based Stress Reduction in the Treatment of Cancer}

Overall, 5 systematic reviews [21-25] - of which one is a metaanalysis [22] - and a comprehensive narrative review [26] have been published. In her recent review, Shennan et al. [21] performed a comprehensive systematic literature review, including 17 quantitative and qualitative studies published between January 2007 and September 2009. The group of authors made a special effort to find and include qualitative studies, since they were explicitly interested in the potential mediators of possible effects. Significant improvements of anxiety, depression, stress level, sexual problems, physiological arousal, immune function as well as other subjectively perceived benefits were described, mostly in female patients. However, the diversity in study design, interventions and patient-therapist contact time was seen as a problem, and the authors claim a need for more high quality randomised controlled trials (RCTs) as well as qualitative studies. Nonetheless, Shennan et al. [21] conclude that mindfulness interventions provide a useful approach for the supportive treatment of cancer patients.

Ledesma and Kumano [22] provided the only meta-analysis on the topic so far. The authors included 10 studies and calculated Cohen's d as a measure of effect on immediate post-intervention data (6-15 weeks). For statistical analysis, the measures were subdivided in measures of mental or physical health, and a considerable effect for improvements in the patients' mental health was found (Cohen's $d=0.48$ ). The authors criticise the small number of eligible studies and the 


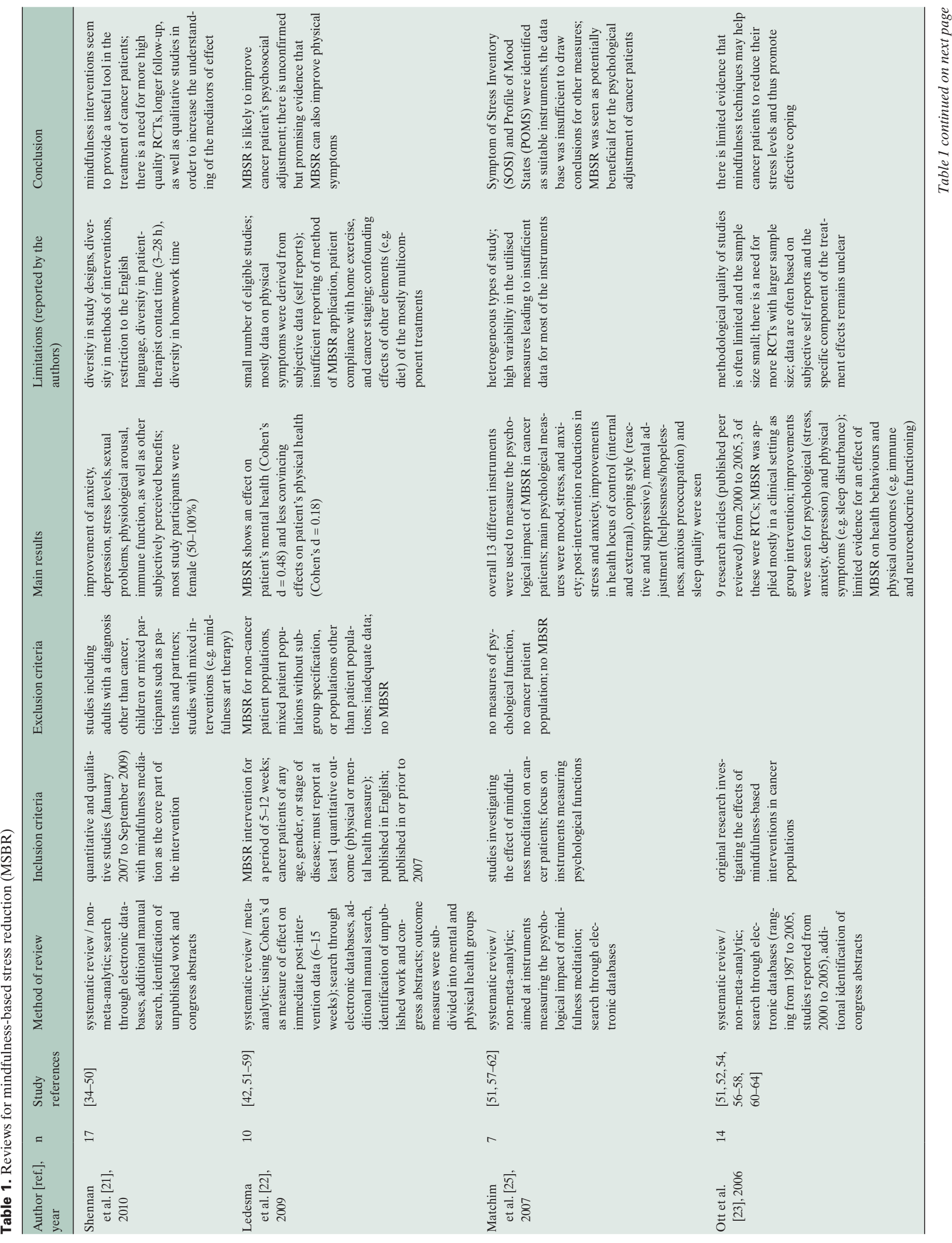




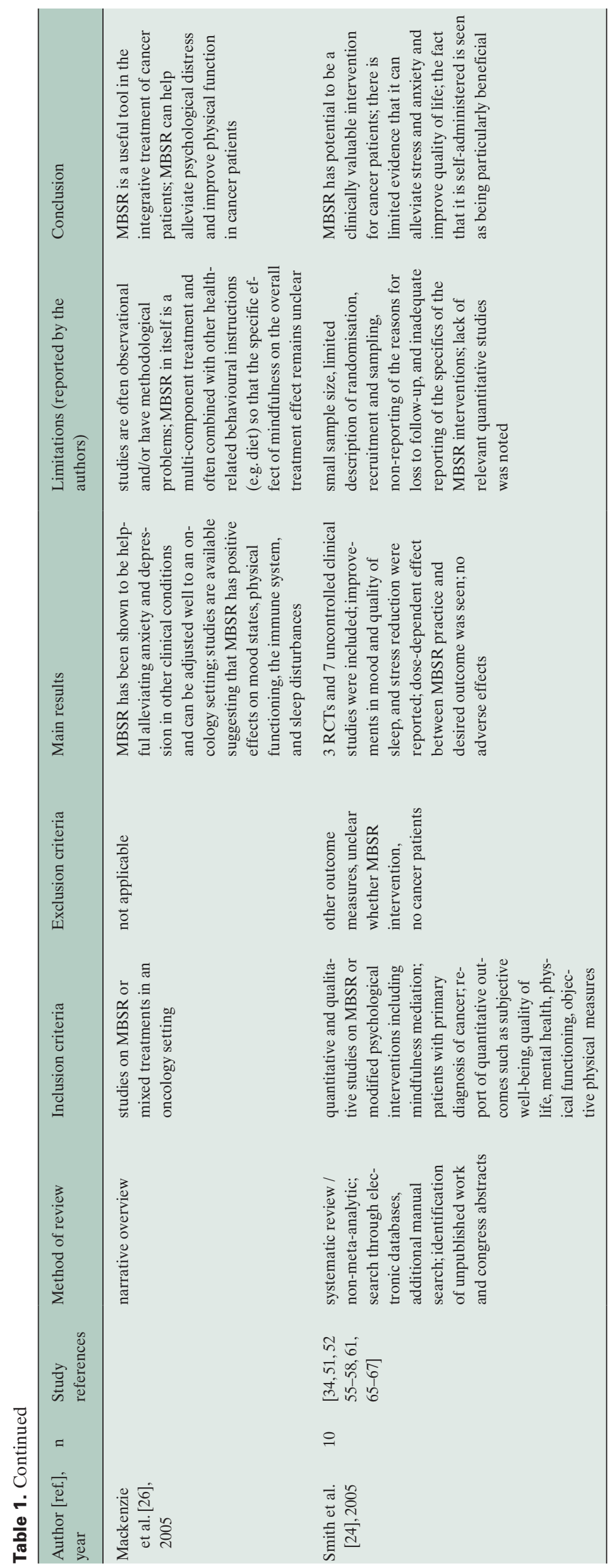

generally low study quality. Furthermore, there was insufficient reporting of the specific MBSR application, patient compliance with home exercise, and cancer staging. Another serious concern was the fact that physical measures were generally derived from subjective reports. Overall, the authors conclude that MBSR is likely to improve the social adjustment of cancer patients and that there is the possibility that it has additional beneficial effects on physical symptoms.

One of the earlier systematic reviews on the question whether mindfulness interventions have beneficial effects in the treatment of cancer was conducted by Ott et al. [23] in 2006, including 9 out of 14 research papers published in peer reviewed journals, 3 of which were RCTs. The authors found that the methodological quality of the studies was limited and sample size rather small. Moreover, the data are often based on subjective self-reports, and the specific component of the treatment effects remains unclear. Nonetheless, Ott et al. [23] conclude that there is some evidence that MBSR helps patients to reduce their stress level and thus may support effective coping.

The first systematic review on the topic was provided by Smith et al. [24] in 2005, who included 3 RCTs and 7 observational studies. Like the other authors of systematic reviews, this group also criticizes the small sample sizes, limited description of randomisation, recruitment and sampling, the non-reporting of the reasons for loss to follow-up, and inadequate reporting of the specifics of the MBSR interventions. Furthermore, a lack of relevant qualitative studies was noted. Nonetheless, these authors also conclude that there is some evidence that MBSR can alleviate stress and anxiety and improve quality of life (QoL). The fact that this technique is self-administered and can be seen as a self-help strategy is evaluated as being particularly beneficial.

One of the major criticisms of almost all authors was the heterogeneity of measures. In 2007, Matchim et al. [25] performed a systematic review focussing on the question which instruments were most valid to measure the effects of MBSR in cancer patients. They included 7 studies and found a total of 13 different instruments utilised for the measurement of the impact of MBSR in cancer patients. Main psychological dimensions were mood, stress, and anxiety. The Symptom of Stress Inventory (SOSI) and the Profile of Mood States (POMS) were identified as suitable instruments to measure the psychological impact of MBSR in cancer patients. Moreover, post-intervention reductions in stress and anxiety, improvements in health locus of control, coping style, mental adjustment, and sleep quality were seen. The authors conclude that MBSR is potentially beneficial for the psychological adjustment of cancer patients.

In summary, most systematic reviews follow the notion of Mackenzie et al.'s [26] most readable narrative review of 2005 that mindfulness interventions are helpful in alleviating anxiety and stress, reduce depression, and help patients to 


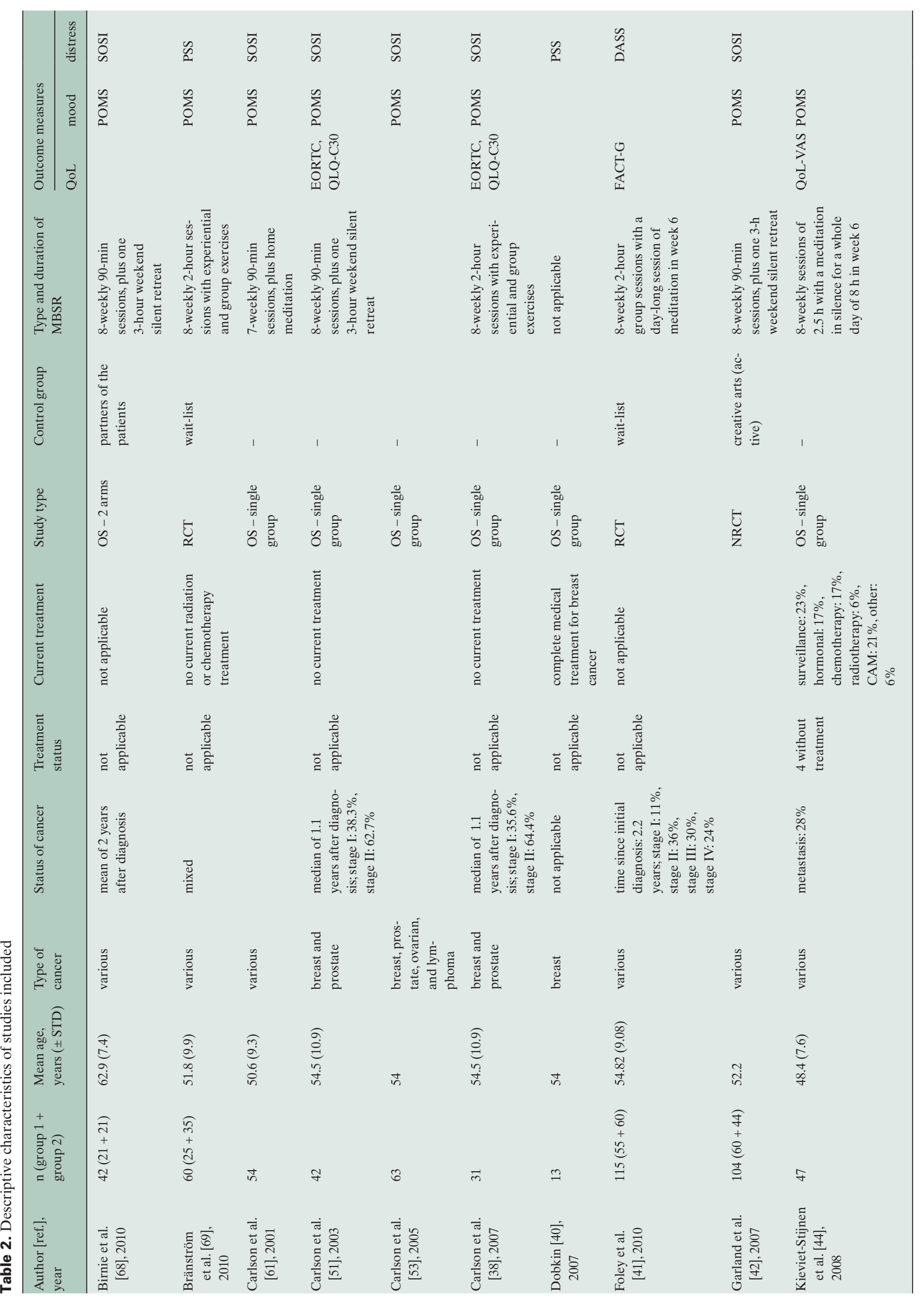

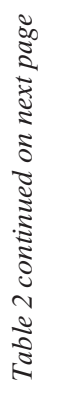




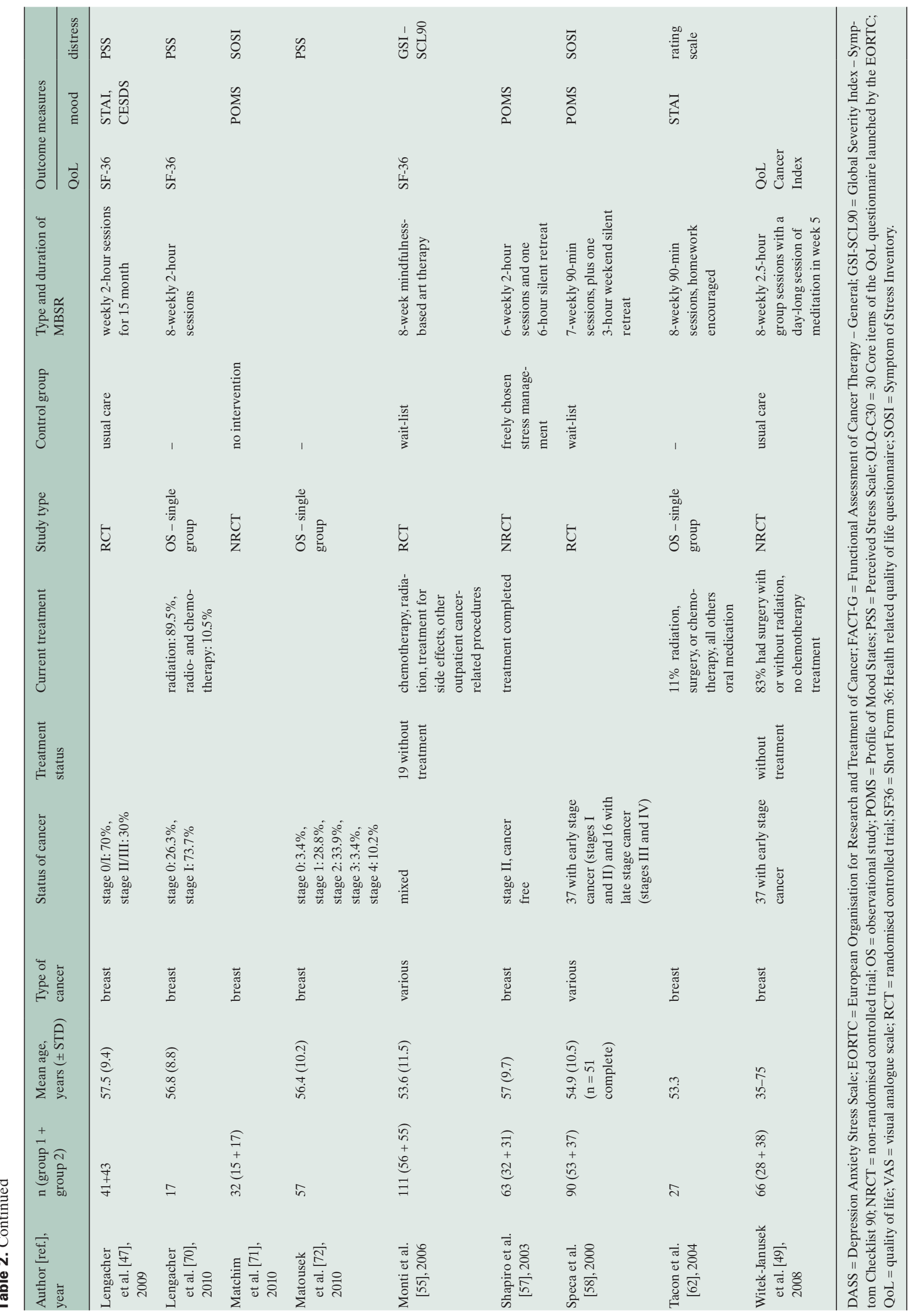


adjust to the challenges associated with a cancer diagnoses. MBSR is likely to reduce psychological distress and may even improve physical function, while no negative side-effects have been reported. It is very well possible to adapt these interventions into an oncology setting, and the authors agree that MBSR may provide a useful tool in the integrative treatment of cancer patients. However, all authors also agree that there are as yet several rather severe limitations to the quality of the available studies. Studies are often observational and/or have methodological problems. Small sample size, heterogeneous designs, and limited reporting have already been mentioned. Moreover, MBSR is in itself a multi-component treatment and is often combined with other health-related behavioural instructions (e.g. diet), and thus the specific effect of mindfulness remains unclear. Another serious problem is the question of generalisation. Most studies were performed in female patient populations, and it is questionable whether mindfulness interventions are as helpful in a male patient population. Moreover, cancer diagnoses vary significantly concerning the time course of the disease and its life-threatening and thus palliative character. It is unclear how effective mindfulness interventions can be when the time course of the disease is rapid, such as in lung or pancreatic cancer.

\section{Specific Aims}

The aim of this paper was to summarise the current evidence for a possible effectiveness of MBSR in the treatment of cancer as comprehensively as possible. Interestingly enough, even though the search strategies and inclusion/exclusion criteria of the 5 systematic reviews were quite similar, not all of them cover the same publications (even if the time periods were comparable). Also, all of them present a slightly different focus of interest which makes it intriguing to combine the available evidence. Overall, all systematic reviews (table 1) suggest that there is convincing evidence that MBSR is beneficial for the relief of psychological symptoms but less so with regard to physical complaints, a finding which is also confirmed by the only currently available meta-analysis on this specific topic [22]. Moreover, even though the existence of 5 systematic reviews suggests that there are enough data available to perform a statistical meta-analysis in order to achieve the highest possible evidence, only one meta-analysis on the specific topic of the role of MBSR in cancer treatment has been performed so far [22]. Therefore, the aim of this paper was i) to combine all available evidence including the data from all systematic reviews to date into 1 overview; ii) to combine all papers available from these sources into one metaanalysis, since although the search strategies and inclusion/ exclusion criteria of the 5 systematic reviews were quite similar, they revealed a slightly different set of publications; and iii) since there is accumulating evidence that beneficial MBSR effects aim at psychological well-being, to provide a differentiated picture of the possible beneficial psychological effects of MBSR in cancer patients.

\section{Material and Methods}

We performed a systematic literature review which included clinical trials of MBSR (including mindfulness-based art therapy) in cancer according to the PRISMA-statement [27, 28]. Two review authors (F.M. and T.O.) independently assessed trials for inclusion in the review. Inclusion criteria were published studies and reviews of MBSR in cancer including observational studies, cohort studies, clinical trials, multicenter studies, RCTs, systematic reviews, and meta-analyses. The studies were requested to involve a structured MBSR programme of at least 6 weeks duration, to involve cancer patients, and to report at least 1 quantitative standardised outcome measure related to QoL, mood, or distress. Exclusion criteria were comments, opinions, programme descriptions and theoretical considerations, and publications in languages other than English and German.

\section{Search Strategy}

The following databases were used to find articles: MEDLINE, EMBASE, AMED, PsycInfo, PsycLit, CCMED, SOMED. We also screened the journal databases of relevant publishers, i.e., gms, Karger, Kluwer, Krause and Pachernegg, Springer, Thieme, and Wiley-Interscience, to find relevant information. Finally, we searched the archive of the specialist library for complementary and alternative medicine (CAM), Witten/ Herdecke University CAMbase [29], for gray literature not listed in the above mentioned databases. The search terms were similar to those of Ledesma and Kumano [22]: mindful, insight meditation, Vipassana, mindfulness-based, cancer, neoplasm, lymphoma, sarcoma and carcinoma. We also screened already existing reviews for further articles that may not have been tracked by this search strategy. All articles found this way were fully read and their reference lists were checked for further relevant publications. To guarantee a certain amount of validity of the selection process, all abstracts of excluded papers were double checked. The search was conducted in January 2011. The reporting of the results adhered to the MOOSE and QUOROM guidelines. The coding of the descriptive factors was performed by A.B. and T.O.; the effect of MBSR on psychological variables was estimated by including data on standardised and validated scales on anxiety, depression, stress and QoL (table 2). Scales were then aggregated as measures on 'QoL', 'mood' or 'distress'.

\section{Statistical Analysis}

In addition to the review of published evidence, a meta-analysis on the effects of MBSR in cancer was carried out. When a trial was found to be eligible, data of pre-post MBSR effects on the dimensions QoL, mood and distress were extracted, entered into a data form, and converted into effect sizes and their standard deviation using a MS-Excel sheet. To calculate the effect size and its standard deviation according to the recommendations of Dunlap et al. [30], the following formulas were utilised:

$d=\frac{m_{1}-m_{2}}{\sqrt{\left(s_{1}^{2}+s_{2}^{2}\right) / 2}}$

$S T D(d)=\sqrt{\frac{2(1-r)}{n}+\frac{d^{2}}{2(n-2)}}$

Effect sizes between 0.5 and 0.8 indicate medium effects, while effect sizes $>0.8$ indicate large effects. Assuming that the studies found by the systematic review are showing different treatment effects with some degree of unknown variability, a random effects model was chosen to calculate overall estimates of the treatment effect according to the recommendations and algorithms given in [31]. Heterogeneity between trials was assessed by standard chi-square tests and the $\mathrm{I}^{2}$ coefficient measuring the percentage of total variation across studies due to true heterogeneity. Results were displayed using a forest plot. Due to the expected small number of eligible studies, further analysis by means of meta-regression was omitted. 


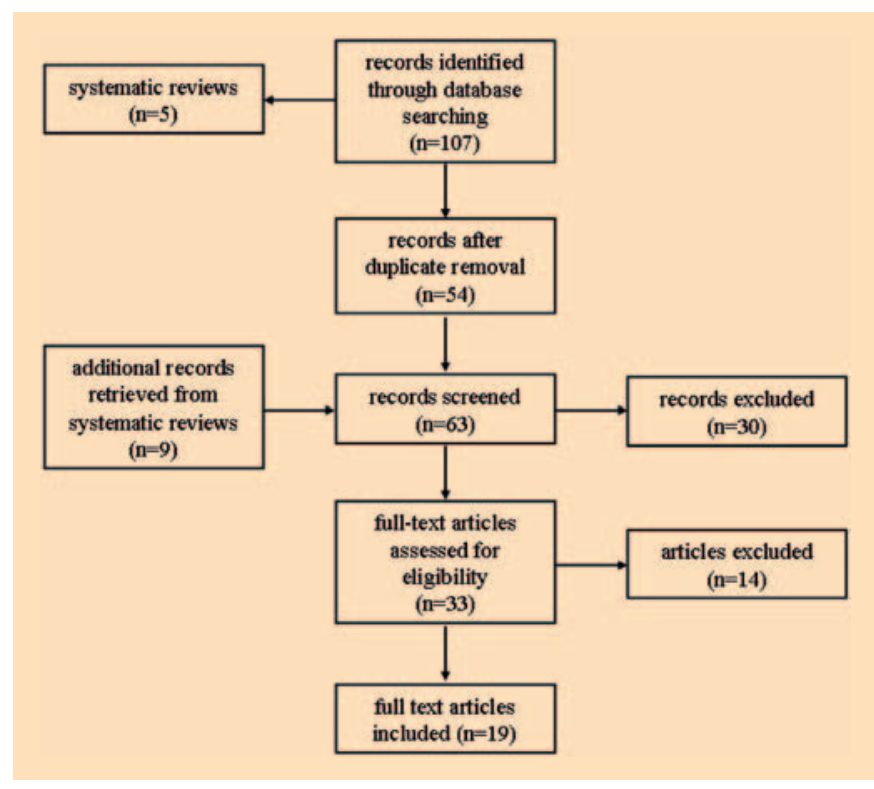

Fig. 1. Flow chart.

\section{Results}

Through data base searching, 107 records were identified. Of these, 54 remained after the removal of duplicates and were screened. An additional total of 9 records were drawn from the reference list of the 5 systematic reviews so that overall 63 records were screened. After screening the abstracts, 30 records were excluded because they did not fit the inclusion/ exclusion criteria. Of the remaining 33 full text articles assessed for eligibility, 14 were excluded according to the inclusion/ exclusion criteria after reading the full text. Therefore a total of 19 studies was included in the systematic review (fig. 1). There were no additional papers retrieved published in German.

Among the 19 studies, 5 were RCTs, 4 were non-randomised controlled trials (NRCTs), and 10 were observational studies (OS) (9 studies had a single group design, and 1 study enrolled 21 couples). The mean number of patients enrolled was $59 \pm 30$ (range 13-115). Most studies clearly described a loss of patients during the course of time, or reported reasons for drop out. Out of the 19 included papers, 9 were performed without a control group and 10 included some kind of experimental control. The type of controls was heterogeneous and mostly passive. In 4 studies, a wait-list control was included, in 2 studies the control consisted of a usual care group (passive), 1 study included a creative arts group (active), 1 study offered a freely chosen stress management (putatively active), and in 1 study the partners of the patients were included as control group. Thus, most controls were chosen in favour of the MBSR intervention. The 19 original papers are summarised in table 2 .

Several different QoL measures were utilised in the included studies, and QoL data were extracted from standard-
Table 3. Effect sizes, number of patients, and standard deviation (STD) for the studies included in the analyses

\begin{tabular}{|c|c|c|c|}
\hline & $\mathrm{n}$ & Cohen's d & $\operatorname{STD}(d)$ \\
\hline \multicolumn{4}{|l|}{ QoL ${ }^{\mathrm{a}}$} \\
\hline Carlson 2003 & 42 & 0.35 & 0.13 \\
\hline Carlson 2007 & 31 & 0.25 & 0.13 \\
\hline Kievet-Stijnen 2008 & 47 & 0.10 & 0.11 \\
\hline Lengacher 2010 & 17 & 0.40 & 0.20 \\
\hline Monti 2006 & 56 & 0.23 & 0.11 \\
\hline Foley 2010 & 55 & 0.48 & 0.11 \\
\hline \multicolumn{4}{|l|}{$\operatorname{Mood}^{\mathrm{b}}$} \\
\hline Birnie 2010 & 21 & 0.36 & 0.18 \\
\hline Carlson 2001 & 54 & 0.51 & 0.13 \\
\hline Carlson 2003 & 42 & 0.06 & 0.12 \\
\hline Carlson 2005 & 63 & 0.57 & 0.11 \\
\hline Carlson 2007 & 31 & 0.00 & 0.14 \\
\hline Matchim 2010 & 15 & 0.71 & 0.24 \\
\hline Kievet-Stijnen 2008 & 47 & 0.28 & 0.11 \\
\hline Speka 2000 & 53 & 0.62 & 0.12 \\
\hline Garland 2007 & 60 & 0.44 & 0.11 \\
\hline Branström 2010 & 60 & 0.76 & 0.12 \\
\hline \multicolumn{4}{|l|}{ Distress $^{c}$} \\
\hline Branström 2010 & 60 & 0.87 & 0.13 \\
\hline Birnie 2010 & 19 & 0.17 & 0.18 \\
\hline Carlson 2001 & 54 & 0.49 & 0.12 \\
\hline Carlson 2003 & 42 & 0.35 & 0.13 \\
\hline Carlson 2005 & 63 & 0.44 & 0.10 \\
\hline Carlson 2007 & 31 & 0.28 & 0.15 \\
\hline Matchim 2010 & 15 & 0.50 & 0.22 \\
\hline Dobkin 2007 & 13 & 1.10 & 0.31 \\
\hline Matousek 2010 & 57 & 0.63 & 0.12 \\
\hline Lengacher 2010 & 17 & 0.72 & 0.23 \\
\hline Monti 2006 & 56 & 0.38 & 0.11 \\
\hline Speka 2000 & 53 & 0.78 & 0.13 \\
\hline Tacon 2004 & 27 & 1.64 & 0.27 \\
\hline Garland 2007 & 60 & 0.49 & 0.11 \\
\hline Foley 2010 & 55 & 0.70 & 0.13 \\
\hline
\end{tabular}

${ }^{\text {a Total of }} \mathrm{n}=248$ patients, overall effect size 0.29 (95\% CI $0.17-0.40$; $\mathrm{p} \leq 0.00005)$, heterogeneity $\mathrm{I}=23.4 \%(\mathrm{Q}=6.53 ; \mathrm{p}=0.26)$.

${ }^{\mathrm{b}}$ Total of $\mathrm{n}=411$ patients, overall effect size 0.42 (95\% CI 0.26-0.58; $\mathrm{p}<0.0001)$, heterogeneity $\mathrm{I}=73.5 \%(\mathrm{Q}=34.0 ; \mathrm{p}=0.0001)$.

'Total of $\mathrm{n}=587$ patients, overall effect size 0.58 (95\% CI $0.45-0.72$; $\mathrm{p}<0.0001)$, heterogeneity $\mathrm{I}=67.2 \%(\mathrm{Q}=45.7 ; \mathrm{p}<0.0001)$.

ised instruments such as the EORTC QLQ-C30, FACT-G or MOS-SF36, and less suited measures such as visual analogue scale (VAS) and QoL Index Cancer (table 2). A total of $\mathrm{n}=248$ patients out of 6 studies was included and the overall effect size was 0.29 (95\% confidence interval (CI) 0.17-0.40; $\mathrm{p} \leq 0.00005)$. Heterogeneity was low with $\mathrm{I}^{2}=23.4 \%(\mathrm{Q}=6.53$; $\mathrm{p}=0.26$ ). Table 3 shows the results of the meta-analysis and figure 2 (a) provides the corresponding forest plots.

Consistently, the POMS was utilised for the measurement of mood states. A total of $n=411$ patients out of 10 studies was included and the overall effect size was 0.42 (95\% CI 
Fig. 2. Forest plots for $\mathbf{A}$ quality of life (QoL), B mood, and C distress. Each dark diamond represents the effect size of the included study while the red diamonds show the overall effect size per dimension.

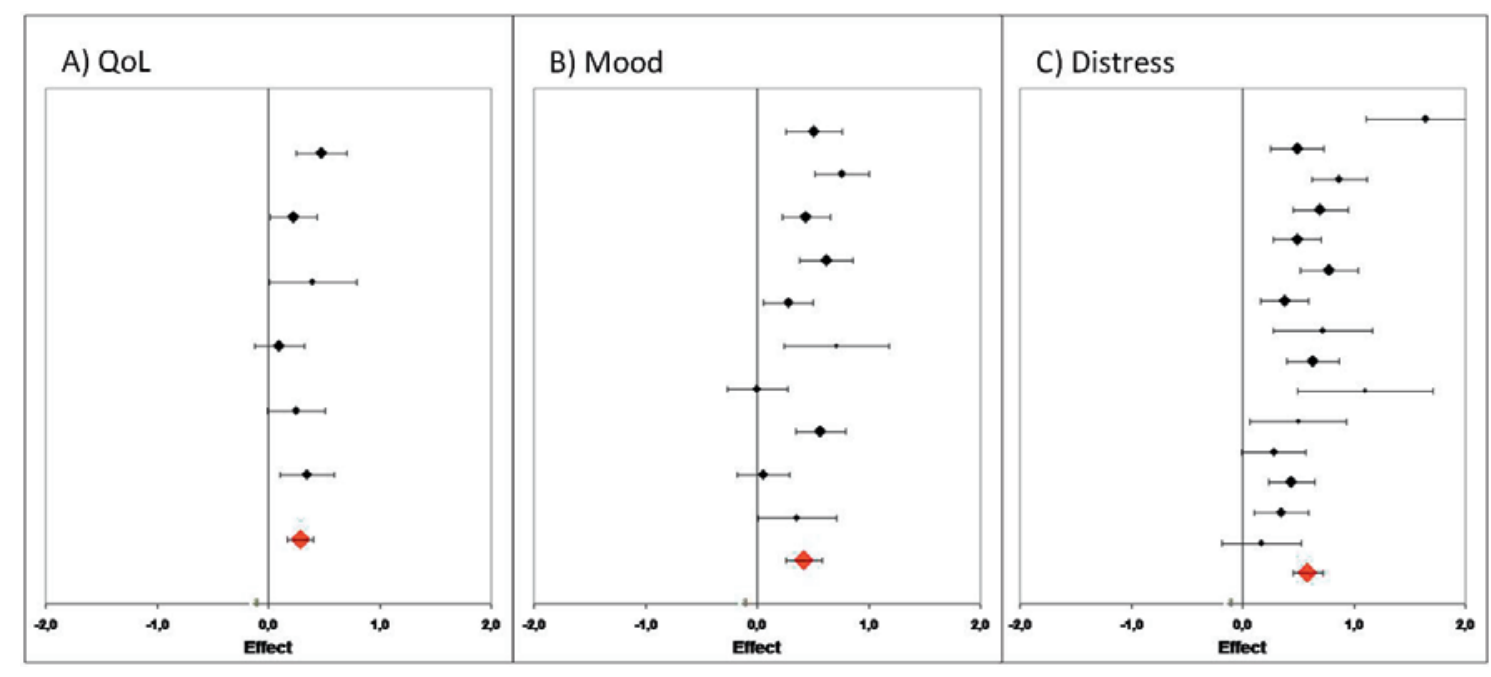

0.26-0.58; $\mathrm{p}<0.0001)$. Even though the instrument used to measure mood was very consistent, heterogeneity was rather high $\mathrm{I}^{2}=73.5 \%(\mathrm{Q}=34.0 ; \mathrm{p}=0.0001)$. Table 3 shows the results of the meta-analysis and figure 2 (b) provides the corresponding forest plot.

Several different measures were used to determine emotional distress, such as the SOSI, PSS, DASS, and the Scl90s Global Severity Index (GSI-SCL90; table 2). A total of $\mathrm{n}=587$ patients out of 15 studies was included. The overall effect size was 0.58 (95\% CI $0.45-0.72 ; \mathrm{p}<0.0001)$ and heterogeneity was high with $\mathrm{I}^{2}=67.2 \%(\mathrm{Q}=45.7 ; \mathrm{p}<0.0001)$. Table 3 shows the results of the meta-analysis and figure 2 (c) the corresponding forest plot.

\section{Discussion}

Helping cancer patients to regain control after being diagnosed with cancer and treated with a variety of therapies such as chemo- or radiotherapy is one of the most challenging tasks for physicians and relatives. MBSR in such situations is supposed to be one of the most powerful mind-body interventions to alleviate psychological symptoms, and several reviews suggest that mindfulness interventions seem to provide a useful tool in the treatment of cancer patients. Potential benefits are seen in the psychological adjustment of cancer patients and in helping them to reduce their stress level and promote their mood by effective coping. Some studies also reveal hints that MBSR may improve physical symptoms leading to an improvement of QoL.

This review assessed for the first time the pre-post effects of MBSR in both, observational and randomised clinical studies, in the dimensions mood, distress, and QoL. Overall, MSBR resulted in rather low effect sizes for QoL, weak effect sizes for mood and moderate effect sizes for emotional distress. Although the pre-post effect sizes presented here are slightly higher and we chose other outcome dimensions, the results are comparable to those reported by Ledesma and Kumano [22] in the dimensions 'mental health measures' (0.48) and 'physical health measures' (0.18). Also in congruence with Ledesma and Kumano [22], a slight decrease in the published effect sizes was detected when only RCTs were included and effect sizes were calculated on the basis of between-group differences. This, however, was not further addressed in our analysis.

Homogeneity measures did not show a consistent picture. While in QoL the $\mathrm{I}^{2}$ value of heterogeneity was quite low and not significant, heterogeneity of included studies on mood and distress was high. Particularly regarding mood measures, this result is interesting because all studies used the well established POMS questionnaire as outcome measure. Thus it must be assumed that either the overall effect size does not represent a homogenous population of cancer patients or that other factors may have biased the results. Indeed, the methodological quality of the investigations on the clinical effects of MBSR may limit the validity of the results. Most trials did not sufficiently report data on compliance and completeness of follow-up, and with the exception of 3 studies, the number of patients did not reach $n=100$ which would be considered sufficient power when testing repeatedly for all dimensions. In particular, the compliance of the patients seems to be the factor being responsible for a high loss in follow-up. In fact, a review of controlled studies on mindfulness meditation and anxiety/depression indicated that if adherence to the programme was assessed (and it was infrequently assessed) 'the relation between practising mindfulness and changes in depression and anxiety was equivocal' [32]. The majority of studies documented pre-post effects of compliant patients, while intent-to-treat analysis was rarely seen. Moreover, one might also argue that in order to identify active ingredients adequate control conditions (e.g. against a progressive muscle relaxation training) should be applied. The review by To- 
neatto and Nguyen [32] supports this assumption, since MBSR had no effect on the outcome parameters when active controls were used in the studies. At least, even though MBSR in some cases was poorly described, the analysis of the papers suggests a homogenous approach of MBSR following the recommendations of Kabat-Zinn [13].

From a clinical point of view, limitations include the heterogeneous cancer staging (it would be important to know at what stage of disease MBSR might be helpful), heterogeneity in types and status of cancer (self-selection of patients may impose a problem: most studies included women with breast cancer), as well as insufficient information and reporting on treatment status and on the concurrent treatments applied. Moreover, the studies generally do not assess whether the cancer patients are emotionally engaged in the interventions and do positively adhere to the interventions. In fact, a potential low inner congruence with the interventions [33] could explain in part the drop outs and loss to follow-up of patients.

\section{Conclusion}

There is evidence that MBSR can improve mood and distress in cancer patient, while physical symptoms are unlikely to improve as a consequence of MBSR interventions. SOSI and POMS are well established in MBSR studies and are identified as suitable and easy to use instruments. However, there is still a need for high quality RCTs with adequate controls, sufficient samples sizes, clear descriptions of patients' psychological profiles, and longer follow-up results. They should moreover be accompanied by qualitative methodology in order to increase the understanding of the mediators of MBSR effects.

\section{Disclosure Statement}

The authors declare that they have no conflict of interest.

\section{References}

1 Derogatis LR, Morrow GR, Fetting J, Penman D, 13 Kabat-Zinn J: An outpatient program in behavPiasetsky S, Schmale AM, Henrichs M, Carnicke CL Jr: The prevalence of psychiatric disorders among cancer patients. JAMA 1983;249:751-757.

$\checkmark 2$ Weisman AD, Worden JW: The existential plight in cancer: significance of the first 100 days. Int J Psychiatry Med 1976;7:1-15.

3 Sellick SM, Crooks DL: Depression and cancer: an appraisal of the literature for prevalence, detection, and practice guideline development for psychological interventions. Psychooncology 1999;8:315-333.

4 Spiegel D, Giese-Davis J: Depression and cancer: mechanisms and disease progression. Biol Psychiatry 2003;54:269-282.

5 McGrath P: Post-traumatric stress and the experience of cancer: a literature review. J Rehabil 1999;65:17-23.

6 Monti DA, Sufian M, Peterson C: Potential role of mind-body therapies in cancer survivorship. Cancer 2008;112(11 suppl):2607-2616.

7 Scott JA, Kearney N, Hummerston S, Molassiotis A: Use of complementary and alternative medicine in patients with cancer: a UK survey. Eur J Oncol Nurs 2005;9:131-137.

${ }_{8}$ Büssing A, Michalsen A, Balzat HJ, Grünther RA, Ostermann T, Neugebauer EA, Matthiessen PF: Are spirituality and religiosity resources for patients with chronic pain conditions? Pain Med 2009;10:327-339.

9 Ernst E, Cassileth BR: The prevalence of complementary/alternative medicine in cancer: a systematic review. Cancer 1998;83:777-782.

10 White P: Complementary medicine treatment of cancer: a survey of provision. Complement Ther Med 1998;6:10-13.

11 Kabat-Zinn J, Massion AO, Kristeller J, Peterson LG, Fletcher KE, Pbert L, Lenderking WR, Santorelli SF: Effectiveness of a meditation-based stress reduction program in the treatment of anxiety disorders. Am J Psychiatry 1992;149:936-943.

12 Kabat-Zinn J: Mindfulness-based intervention in context: past, present and future. Clin Psychol Sci Pract 2003;10:144-156.
Kabat-Zinn J: An outpatient program in behav-
ioral medicine for chronic pain patients based on the practice of mindfulness meditation: theoretical considerations and preliminary results. Gen Hosp Psychiatry 1982;4:33-47.

14 Grossman P, Niemann L, Schmidt S, Walach H: Mindfulness-Based Stress Reduction and health benefits: a meta-analysis. J Psychosom Res 2004;57: 35-43.

15 Kabat-Zinn J: Four year follow-up of a meditationbased program for the self-regulation of chronic pain: treatment outcomes and compliance. Clin J Pain 1987:2:159-173.

16 Kaplan KH, Goldenberg DL, Galvin-Nadeau M: The impact of a meditation-based stress reduction program on fibromyalgia. Gen Hosp Psychiatry 1993:15:284-289.

17 Miller J, Fletcher K, Kabat-Zinn J: Three-year follow-up and clinical implications of a mindfulness meditation-based stress reduction intervention in the treatment of anxiety disorders. Gen Hosp Psychiatry 1995;17:192-200.

18 Teasdale JD, Segal ZV, Williams JMG, Ridgeway VA, Soulsby JM, Lau MA: Prevention of relapse/ recurrence in major depression by mindfulnessbased cognitive therapy. J Consult Clin Psychol 2000;68:615-623.

19 Williams K, Kolar M, Reger B, Pearson J: Evaluation of a wellness-based mindfulness stress reduction intervention: a controlled trial. Am J Health Promot 2001;15:422-432.

20 Williams M, Teasdale J, Segal Z, Soulsby J: Mindfulness-based cognitive therapy reduces overgeneral autobiographical memory in formally depressed patients. J Abnormal Psychol 2000;109: 150-155.

21 Shennan C, Payne S, Fenlon D: What is the evidence for the use of mindfulness-based interventions in cancer care? A review. Psychooncology 2011;20:681-697.

22 Ledesma D, Kumano H: Mindfulness-based stress reduction and cancer: a meta-analysis. Psychooncology 2009;18:571-579.
23 Ott MJ, Norris RL, Bauer-Wu SM: Mindfulness meditation for oncology patients: a discussion and critical review. Integr Cancer Ther 2006;5:98-108.

24 Smith JE, Richardson J, Hoffman C, Pilkington $\mathrm{K}$ : Mindfulness-Based Stress Reduction as supportive therapy in cancer care: systematic review. J Adv Nurs 2005;52:315-327. Erratum in J Adv Nurs 2006;53:618.

25 Matchim Y, Armer JM: Measuring the psychological impact of mindfulness meditation on health among patients with cancer: a literature review. Oncol Nurs Forum 2007;34:1059-1066.

26 Mackenzie MJ, Carlson LE, Speca M: Mindfulness-based stress reduction (MBSR) in oncology: rationale and review. Evid Base Integr Med 2005; 2:139-145.

27 Liberati A, Altman DG, Tetzlaff J, Mulrow C, Gøtzsche PC, Ioannidis JP, Clarke M, Devereaux PJ, Kleijnen J, Moher D: The PRISMA statement for reporting systematic reviews and meta-analyses of studies that evaluate healthcare interventions: explanation and elaboration. BMJ 2009;339:b2700.

28 Moher D, Liberati A, Tetzlaff J, Altman DG; PRISMA Group: Preferred reporting items for systematic reviews and meta-analyses: the PRISMA statement. BMJ 2009;339:b2535.

29 Ostermann T, Raak CK, Matthiessen PF, Büssing A, Zillmann H: Linguistic processing and classification of semi structured bibliographic data on complementary medicine. Cancer Informatics 2009; 7:159-169.

30 Dunlap WP, Cortina JM, Vaslow JB, Burke MJ: Meta-analysis of experiments with matched groups or repeated measures designs. Psychol Meth 1996;1: 170-177.

31 Borenstein M, Hedges LV, Higgins JT, Rothstein $\mathrm{H}$ : Introduction to Meta-Analysis. Chichester, John Wiley \& Sons Ltd., 2009.

32 Toneatto T, Nguyen L: Does mindfulness meditation improve anxiety and mood symptoms? A review of the controlled research. Can J Psychiatry 2007:52:260-266. 
33 Büssing A, Edelhäuser F, Weisskircher A, Fouladbakhsh JM, Heusser P: Inner correspondence and feelings of peaceful easiness in participants practicing Eurythmy Therapy and Yoga: a validation study. Evid Based Complement Alternat Med (eCAM) 2011; doi: 10.1155/2011/329023.

34 Bauer-Wu S, Sullivan AM, Rosenbaum E, et al.: Facing the challenges of hematopoietic stem cell transplantation with mindfulness meditation: a pilot study. Integr Cancer Ther 2008;7:62-69.

35 Branstrom R: Effects of mindfulness meditation training on quality of life, anxiety, stress and positive mood in women with cancer. Ann Behav Med 2008;35:46.

36 Brotto LA, Heiman JR, Goff B, et al.: A psychoeducational intervention for sexual dysfunction in women with gynecologic cancer. Arch Sex Behav 2008;37:317-329.

37 Brotto LA, Heiman JR: Mindfulness in sex therapy: applications for women with sexual difficulties following gynecologic cancer. Sex Relationship Ther 2007;22:3-11.

38 Carlson LE, Speca M, Faris P, Patel KD: One year prepost intervention follow-up of psychological, immune, endocrine and blood pressure outcomes of mindfulness-based stress reduction (MBSR) in breast and prostate cancer outpatients. Brain Behav Immun 2007;21:1038-1049.

\$3 Chadwick P, Newell T, Skinner C: Mindfulness groups in palliative care: a pilot qualitative study. Spirituality Health Int 2008;9:135-144.

40 Dobkin P: Mindfulness-based stress reduction: what processes are at work? Complement Ther Clin Pract 2008;14:8-16.

41 Foley E, Baillie A, Huxter M, Price M, Sinclair E: Mindfulness based cognitive therapy for individuals whose lives have been affected by cancer: a randomized controlled trial. J Consult Clin Psychol 2010;78:72-79.

42 Garland SN, Carlson LE, Cook S, Lansdell L, Speca M: A non-randomized comparison of mindfulness-based stress reduction and healing arts programs for facilitating post-traumatic growth and spirituality in cancer outpatients. Support Care Cancer 2007;15:949-961.

43 Hoffman C: MBSR Doctoral Research Study. Personal communication.

44 Kieviet-Stijnen A, Visser A, Garssen B, Hudig W: Mindfulness-based stress reduction training for oncology patients: patients' appraisal and changes in wellbeing. Patient Educ Counsel 2008;72:436-442.

45 Kingston T: The effect of a mindfulnss based $\operatorname{cog}$ nitive therapy imtervention on distress in cancer outpatients. Abstract presented on the International Spiritual Care Conference April 27-28, 2009, Killarney, Ireland; www.spiridualcareconference. com/x/file/ConferencePosterAbstracts 2.pdf

46 Lengacher CA, Kip KE, Moscoso M, JohnsonMallard VP, Molinari, M, Gaurkee D, Mierzejewski A, Jacobsen P, Cox CE, Greenberg H: Mindfulness-based stress reduction improves psychological status and general health among breast cancer survivors. Psychooncology 2007;16:72-73.
47 Lengacher CA, Johnson-Mallard V, Post-White J, Moscoso MS, Jacobsen PB, Klein TW, Widen RH, Fitzgerald SG, Shelton MM, Barta M, Goodman M, Cox CE, Kip KE: Randomized controlled trial of mindfulness-based stress reduction (MBSR) for survivors of breast cancer. Psychooncology 2009; 18:1261-1272.

48 Mackenzie MJ, Carlson LE, Munoz M, Speca M: A qualitative study of self-perceived effects of mindfulness-based stress reduction (MBSR) in a psychosocial oncology setting. Stress Health J Int Soc Invest Stress 2007;23:59-69.

49 Witek-Janusek L, Albuquerque K, Chroniak KR, Chroniak C, Durazo-Arvizu R, Mathews HL: Effect of mindfulness based stress reduction on immune function, quality of life and coping in women newly diagnosed with early stage breast cancer. Brain Behav Immun 2008;22(6):969-981.

50 Wurtzen H, Elsass P, Sumbundu A, Flyger H, Johansen C: Mindfulness based stress reduction (MBSR): preliminary results of an RCT of MBSR intervention among Danish women diagnosed with breast cancer. Psychooncology 2008;17:276-277.

51 Carlson LE, Speca M, Patel KD, Goodey E: Mindfulness- based stress reduction in relation to quality of life, mood, symptoms of stress, and immune parameters in breast and prostate cancer outpatients. Psychosom Med 2003;65:571-581.

52 Carlson LE, Speca M, Patel KD, Goodey E: Mindfulness- based stress reduction in relation to quality of life, mood, symptoms of stress and levels of cortisol, dehydroepiandrosterone sulfate (DHEAS) and melatonin in breast and prostate cancer outpatients. Psychoneuroendocrinology 2004;29:448-474.

53 Carlson LE, Garland SN: Impact of mindfulnessbased stress reduction (MBSR) on sleep, mood, stress and fatigue symptoms in cancer outpatients. Int J Behav Med 2005;12:278-285.

54 Herbert JR, Ebbeling CB, Olendzki BC, Hurley TG, Ma Y, Saal N, Ockene JK, Clemow L: Change in women's diet and body mass following intensive intervention for early-stage breast cancer. J Am Diet Assoc 2001;101:421-431.

55 Monti DA, Peterson C, Kunkel EJ, Hauck WW, Pequignot E, Rhodes L, Brainard GC: A randomized, controlled trial of mindfulness-based art therapy (MBAT) for women with cancer. Psychooncology 2006;15:363-373.

56 Saxe GA, Hebert JR, Carmody JF, Kabat-Zinn J, Rosenzweig PH, Jarzobski D, Reed GW, Blute RD: Can diet in conjunction with stress reduction affect the rate of increase in prostate specific antigen after biochemical recurrence of prostate cancer? J Urol 2001;166:2202-2207.

57 Shapiro SL, Bootzin RR, Figueredo AJ, Lopez AM, Schwartz GE: The efficacy of mindfulnessbased stress reduction in the treatment of sleep disturbance in women with breast cancer: an exploratory study. J Psychosom Res 2003;54:85-91.

58 Speca M, Carlson LE, Goodey E, Angen M: A randomized, wait-list controlled clinical trial: the effect of a mindfulness meditation-based stress reduction program on mood and symptoms of stress in cancer outpatients. Psychosom Med 2000;62:613-622.
59 Tacon AM, Ronaghan C: Mindfulness, psychosocial factors, and breast cancer. J Cancer Pain Symptom Palliation 2005;1:45-53.

60 Brown KW, Ryan RM: The benefits of being present: mindfulness and its role in psychological well-being. J Pers Soc Psychol 2003;84:822-848.

61 Carlson LE, Ursuliak Z, Goodey E, Angen M, Speca M: The effects of a mindfulness meditationbased stress reduction program on mood and symptoms of stress in cancer outpatients: 6-month follow-up. Support Care Cancer 2001;9:112-123.

62 Tacon AM, Caldera YM, Ronaghan C: Mindfulness-based stress reduction in women with breast cancer. Families Systems Health. 2004;22:193-203.

63 Mackenzie M, Carlson L, Munoz M: Understanding the self-perceived effects of ongoing Mindfulness-Based Stress Reduction (MBSR) on cancer patients: a grounded theory approach. Paper presented at: Integrating Mindfulness-Based Interventions into Medicine, Health Care, and Society, Worcester, MA, March 30 - April 2, 2004.

64 Moscoso M, Reheiser E, Hann D: Effects of a brief Mindfulness-Based Stress Reduction intervention on cancer patients. Paper presented at: First Annual Conference of the American Psychosocial Oncology Society, Orlando, FL, 2004.

65 Altman K: A Brief Therapy Model to Reduce Stress by Practicing Breathing Exercises, Mindful Meditation, and Yoga Stretching. Capella University, 2001.

66 Majumdar M, Grossman P, Dietz-Waschkowski B, Kersig S, Walach H: Does mindfulness meditation contribute to health? Outcome evaluation of a German sample. J Altern Complement Med 2002;8:719-730.

67 Spahn G, Lehmann N, Franken U, Paul A, Langhorst J, Michalsen A, Dobos GJ: Improvement of fatigue and role function of cancer patients after an outpatient integrative mind-body intervention. Focus Alternative Compl Ther 2003;8:540.

68 Birnie K, Garland SN, Carlson LE: Psychological benefits for cancer patients and their partners participating in mindfulness-based stress reduction (MBSR). Psychooncology 2010;19:1004-1009.

69 Bränström R, Kvillemo P, Brandberg Y, Moskowitz JT: Self-report mindfulness as a mediator of psychological well-being in a stress reduction intervention for cancer patients - a randomized study. Ann Behav Med 2010;39:151-161.

70 Lengacher CA, Johnson-Mallard V, Barta M, Fitzgerald S, Moscoso MS, Post-White J, Jacobsen PB, Shelton MM, Le N, Budhrani P, Goodman M, Kip KE: Feasibility of a mindfulnessbased stress reduction program for early-stage breast cancer survivors. J Holist Nurs 2010; doi: 10.1177/0898010110385938

71 Matchim Y, Armer JM, Stewart BR: Effects of Mindfulness-Based Stress Reduction (MBSR) on health among breast cancer survivors. West J Nurs Res 2010; doi: 10.1177/0193945910385363

72 Matousek RH, Dobkin PL, Pruessner J: Cortisol as a marker for improvement in mindfulness-based stress reduction. Complement Ther Clin Pract 2010;16:13-19. 